\title{
Diospyrobezoar: an uncommon cause of obstructive ileus
}

\author{
Bas de Groot • Julien B. C. M. Puylaert
}

Received: 16 June 2008 / Accepted: 22 September 2008 / Published online: 14 November 2008

(C) Springer-Verlag London Ltd 2008

A 40-year-old Hindustani male, with a past medical history of acetic acid intoxication, presented to the emergency department with cramping epigastric pain. The pain was reminiscent of the pain he had experienced 2 weeks before. At that time, his pain had resolved at presentation to the emergency department and he was discharged home with a proton pump inhibitor for the diagnosis of "peptic ulcer". An ultrasound performed on the following day showed a dilated small intestine with intra-luminal fluid suggestive of a period of transient obstruction. The ultrasound (Fig. 1) and subsequent abdominal computed tomography (CT) scan (Fig. 2a,b) made during the present visit to the emergency department, with his pain still present, depict two intra-luminal foreign bodies.

B. de Groot

Department of Emergency Medicine, Medical Centre Haaglanden, Den Haag, The Netherlands

\section{J. B. C. M. Puylaert}

Department of Radiology, Medical Centre Haaglanden,

Den Haag, The Netherlands

B. de Groot $(\bowtie)$

Afdeling Spoedeisende Hulp, Medical Centre Haaglanden,

Location Westeinde,

Lijnbaan 32,

2501 CK Den Haag, The Netherlands

e-mail: jobas@compaqnet.nl
A bezoar is an accumulation of ingested foreign material. Three major categories exist, depending on their composition: trichobezoar, formed by ingested hair, pharmacobezoar, formed by indigestible medication contents, and phytobezoar formed by indigestible food fibres, most commonly the diospyrobezoar, which consists of persimmon fruit, which was eaten by our patient in large quantities $[1,2]$. The indigestible food fibres form a mass and finally an obstructive ileus. Diagnosis is usually made by CT scan or ultrasound. Conservative treatment modalities described are endoscopic removal, pulverizing the bezoar with YAG laser therapy or extra-corporal shock wave lithotripsy, or chemical dissolution of the bezoar with for instance cellulase or Coca-Cola [2, 3]. Our patient was advised to drink 31 of Coca-Cola every $24 \mathrm{~h}$ to dissolve the cellulose

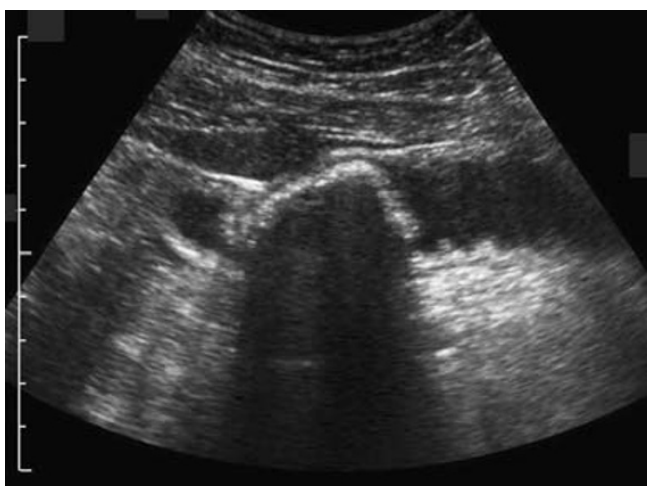

Fig. 1 Ultrasound of the abdomen showing dilated small intestine with an intra-luminal foreign body 

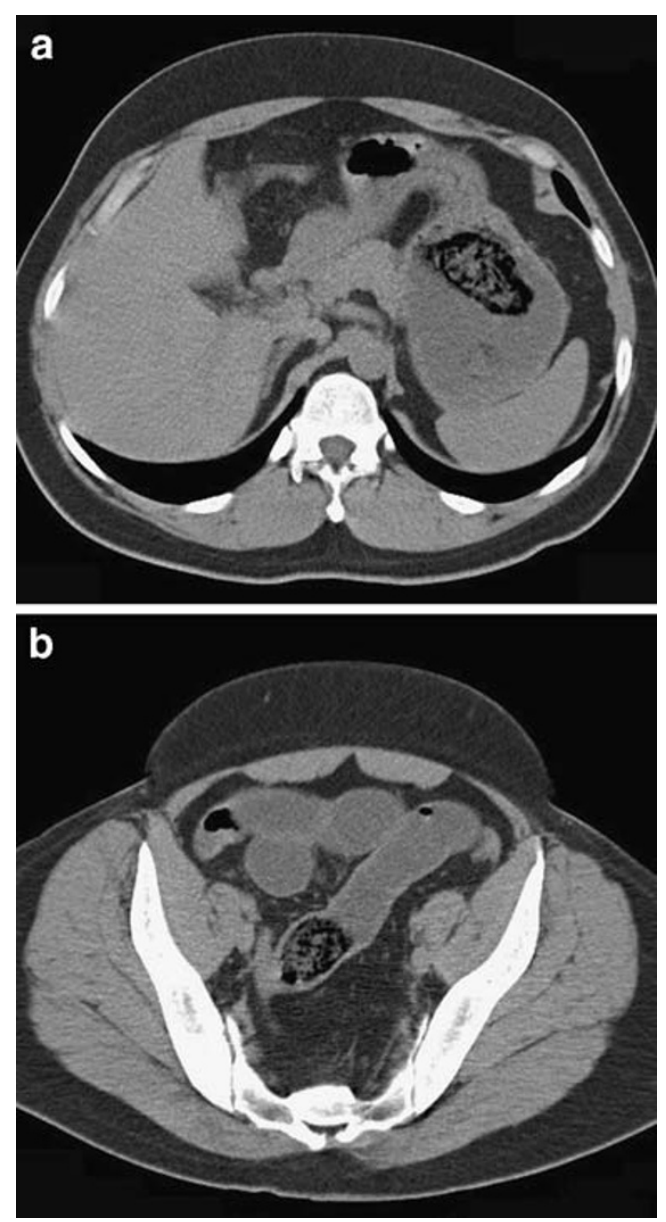

Fig. 2 CT scan of the abdomen showing one foreign body in the stomach (a) and one in the dilated duodenum (b) in the diospyrobezoar. At follow-up, his complaints and the duodenal bezoar had disappeared, while the bezoar in the stomach was still present.

\section{References}

1. Phillips MR, Zaheer S, Drugas GT (1998) Gastric trichobezoar: case report and literature review. Mayo Clin Proc 73(7):653656

2. Serour F, Dona G, Kaufman M, Weisberg D, Krispin M (1985) Acute intestinal occlusion caused by phytobezoars in Israel. Role of oranges and persimmons (in French). J Chir (Paris) 122:299-304

3. Walker-Renard P (1993) Update on the medicinal management of phytobezoars. Am J Gastroenterol 88:1663-1666 